\title{
Evaluating Equity in Health Financing Using Benefit Incidence Analysis: A Framework for Accounting for Quality of Care
}

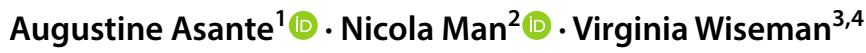

Published online: 22 June 2020

(c) The Author(s) 2020, corrected publication 2020

\begin{abstract}
Equity in health care financing has gained increased attention in low- and middle-income countries (LMICs) following the renewed global interest in universal health coverage (UHC), a key component of the sustainable development goals (SDGs). UHC requires that people have access to the health services they need without risking financial hardship. Health financing is central to UHC and many LMICs have initiated reforms to align their health financing systems with the goals of UHC. Evaluation of the equity impact of these reforms has become a growing area of research, especially in countries with large health inequalities where the pressure to move towards UHC is most intense and the need for evidence to inform policy most critical. However, current analytical tools for evaluating equity in health financing conspicuously exclude indicators of quality, an important dimension of UHC. The aim of this paper was to address this critical methodological gap by introducing quality scores into benefit incidence analysis (BIA), one of the key techniques for assessing equity in health financing. BIA measures the extent to which different socioeconomic groups benefit from public spending on health care through their use of health services. The benefit (public subsidy) is captured in monetary terms by multiplying the quantity of a particular health service consumed by the unit cost of that service and subtracting any out-of-pocket costs incurred while using the service. It does not account for variations in the quality of health services in the computation of the public subsidy.
\end{abstract}

\section{Introduction}

Equity in health care financing has become topical once again following renewed global interest in universal health coverage (UHC). The sustainable development goal (SDG) target 3.8 deals with achieving UHC, including financial risk protection, access to quality essential health care services and access to safe, effective, quality and affordable essential medicines and vaccines for all [1]. This strong emphasis on equity is borne out of widespread concerns that the poor

Augustine Asante

a.asante@unsw.edu.au

1 School of Public Health and Community Medicine, University of New South Wales (UNSW) Sydney, Room 238, Level 2 Samuels Building, Sydney, NSW 2052, Australia

2 National Drug and Alcohol Research Centre, University of New South Wales (UNSW) Sydney, Sydney, NSW, Australia

3 Department of Global Health and Development, London School of Hygiene and Tropical Medicine, London, UK

4 Kirby Institute, University of New South Wales (UNSW), Sydney, NSW, Australia and other vulnerable population groups worldwide have inadequate access to quality health care [2]. It is estimated that at least half of the world's 7.3 billion people do not receive the essential health services they need [3]. Often those with the greatest need for health care have the least access - an inverse care law of a sort [4]. Governments of low- and middle-income countries (LMICs) are under pressure to implement pro-poor policies that will address current inequities in health, not only by increasing their overall share of health spending but also ensuring that the poor receive an appropriate share of any increased spending [5].

Paying for health services out-of-pocket (OOP) at the point of use is a major hinderance to access, stopping millions of people globally from accessing needed health care and pushing millions further into poverty [6, 7]. Health systems that rely heavily on OOP payments as a major source of finance tend to provide little financial protection [8]. Despite this, OOP payments constitute a significant proportion of total health expenditure across LMICs. In sub-Saharan Africa, OOP payments average around $36 \%$ of total health expenditure [9]. Southeast Asian countries such as Cambodia and Myanmar have around $60 \%$ of their total health expenditures coming from OOP payments, and it is welldocumented that a significant proportion of households in 


\section{Key Points for Decision Makers}

Benefit incidence analysis (BIA) is one of the key methodologies for assessing equity in health financing and involves measuring the extent to which different socioeconomic groups benefit from public spending on health care through their use of health services.

To compute the health care benefit (public subsidy), BIA combines the quantity of health services utilised and the unit costs of those services, less any out-of-pocket costs incurred while using these services.

A major weakness of BIA is that it does not account for variations in the quality of services received by different people, leading to a potential under/over-estimation of the subsidy. The framework described in this paper demonstrates that it is possible to account for the quality of health services in the computation of the public subsidy under BIA.

these countries experience catastrophic payment typically defined as out-of-pocket health payments that exceed a certain proportion of a household's income [10-12]. A recent Lancet publication indicates that around $15 \%$ of households in Myanmar incurred catastrophic payments and 2\% of non-poor households were impoverished as a result of OOP health expenditure [13]. A key dimension of UHC therefore is financial protection, which ensures that people do not suffer catastrophic payments and are not pushed into poverty as a result of using health care.

Many LMICs are taking action to improve equity in health financing and delivery by initiating (or strengthening existing) pro-poor reforms to align their health systems with the goals of UHC [14]. Indonesia, for example, has embarked on one of the world's largest single-payer health financing systems in a bid to make health services available to its population of around a quarter of a billion people $[15,16]$. The country's Jaminan Kesehatan Nasional (JKN) scheme, which has over 165 million enrolment, brings together all major health insurance schemes in Indonesia under a single agency - the Social Security Management Corporation for the Health Sector (BPJS Kesehatan) [16]. Other countries, including Thailand, Ghana, Tunisia and Peru, have all implemented UHC-focused health financing reforms in an attempt to extend coverage and financial protection over the past decade [17-19].

Assessing the impact of these reforms on equity is becoming a growing area of research, especially in countries with large inequities in health where the pressure to move towards UHC is intense and the need for evidence to inform policy is most critical. The World Bank launched an evaluation of UHC programmes in nearly 24 developing countries in 2013 with the objective of sharing knowledge regarding propoor reforms being implemented across these countries [20]. Other multi-country evaluations aiming to advance UHC have been undertaken over the past few years $[12,19,21]$. The global interest in UHC has, to a large extent, refocused attention on methodologies for assessing equity in health financing. Quantitative techniques such as measures of catastrophic health payments, financing incidence or progressivity analysis and benefit incidence analysis (BIA) are among the suite of analytical tools increasingly applied in UHCrelated research in LMICs [22].

While together these approaches provide valuable evidence on the pro-poorness of health financing systems, they are all conspicuously silent on the issue of quality. UHC emphasises access to quality health services and not just any health service. The Lancet Commission on High Quality Health Systems notes, among other things, that "poor-quality health care is common across conditions and countries, with the poor and most vulnerable the worst affected" [23]. Lowquality health care yields lesser benefits and given the variations in quality of health care across countries, not accounting for quality in an assessment of the distribution of public subsidies for health would most likely lead to misleading conclusions about who benefits most from government health spending. This paper attempts to address this critical methodological gap by introducing a quality score into the computation of public subsidies for health under BIA. To the best of our knowledge, this is the first ever attempt to expand the analytical technique of BIA to incorporate measures of health care quality.

\section{A Brief Overview of Benefit Incidence Analysis}

BIA estimates the distributional impact of public spending on health care by measuring the extent to which different socioeconomic groups benefit from government health spending through their use of health services $[24,25]$. It reveals the pro-poorness of health care delivery systems and the extent to which those who need health services benefit in accordance with need. BIA typically focuses on the distribution of public subsidies for the provision of health care. Although not always stated, government subsidies for health care are expected to benefit the poor and most disadvantaged more than the better-off [26]. This is because poor people often have inadequate access to social services such as health care, which contributes to their state of poverty. There are therefore sound equity grounds for public funds to be targeted at the poor $[5,27]$.

BIA involves a number of steps, including ranking the study population by a living standard measure, assessing 
the rate of utilisation of different types of health services, estimating the unit cost of each type of service, and multiplying the utilisation rates and unit costs to determine the amount of public subsidy 'captured' by a particular group of people. The unit cost of services can be estimated under different assumptions. Wagstaff [24] has discussed in detail the different unit cost assumptions, which include the constant unit-cost, constant unit-subsidy and proportional unit-cost assumption. Under the constant unit-cost assumption, each type of service (e.g. each health centre visit) is assumed to cost the same and is equal to the total costs incurred in delivering that type of service (i.e. subsidies plus user fees) divided by the number of units of utilisation [28]. Under this assumption, the more fees one pays for a given unit of utilisation, the smaller is the subsidy they receive [24]. The constant unit-subsidy assumption regards the unit subsidy to be uniform across all units of care of a particular service type. It is obtained by dividing the total subsidies for the service in question by the number of units of utilisation of that service. The computation here disregards any OOP payments by the user, making the subsidy proportional to utilisation [24]. Finally, the proportional unit-cost approach assumes that costs and fees are proportional to one another, i.e. the unit cost of a service is proportionate to the unit fee paid by the user for that service. A higher user fee for a particular type of care therefore suggests a more costly type of care was received, making the total subsidy received proportional to the total fees paid [29]. In this study we adopted the constant unit cost assumption because of its simplicity and limited data requirements.

\section{Defining and Measuring Quality of Health Care}

'Quality' as used in the health sector describes the "degree to which health services for individuals and populations increase the likelihood of desired health outcomes and are consistent with current professional knowledge" [30]. Health services refer to all services dealing with the diagnosis and treatment of disease, or the promotion, maintenance and restoration of health. These include personal and non-personal health services [31]. Different approaches have been advanced for the measurement of health care quality. The Donabedian quality framework of structure, process and outcomes, and its associated seven pillars of quality (efficacy, effectiveness, efficiency, optimality, acceptability, legitimacy and equity) has been widely used to assess health service quality [32].

Structural quality is defined as the physical and organisational aspects of the health care setting (e.g. facilities, geographical location, equipment, personnel, etc., that support the process of care) [32]. Processes of patient care rely on the structures available to carry out patient care activities and they are performed in order to improve patient health (outcomes) in terms of promoting recovery, functional restoration, survival and patient satisfaction [32]. Under the process dimension, perceptions about best practices of health personnel, including issues such as health workers showing compassion and support, showing respect, being honest with patients, doctors making accurate diagnoses, prescribing appropriate drugs, etc., are assessed. Outcome measures typically focus on the effects of treatment, or more generally whether care has improved patient health [32]. While outcome measures typically focus on the users of health care, perceptions among non-users are equally relevant as they may provide insights into the likelihood of services being used.

\section{Weighting Public Subsidies by Quality Score}

The main objective of this paper is to introduce a score for quality of care into the computation of public subsidy under BIA. We followed existing approaches for computing the public subsidy captured by households (grouped into socioeconomic/wealth quintiles) through their use of health services $[24,33]$. The amount of subsidy received by each household is represented by the costs incurred by the provider in providing the service minus any fees paid by the household (user) to the provider in using the service (Eq. 1):

$S_{\mathrm{ph}}=C_{\mathrm{ph}}-F_{\mathrm{ph}}=c_{\mathrm{ph}} q_{\mathrm{ph}}-f_{\mathrm{ph}} q_{\mathrm{ph}}=q_{\mathrm{ph}}\left(c_{\mathrm{ph}} f_{\mathrm{ph}}\right)=s_{\mathrm{ph}} q_{\mathrm{ph}}$

where $S_{\text {ph }}$ is the subsidy captured by household $h$ from facility $p$ (e.g. health centre or hospital outpatient department); $C_{\mathrm{ph}}$ is the cost incurred by the provider in facility $p$ in providing the service to household $h ; F_{\mathrm{ph}}$ is the total fee paid by household $h$ to the provider in facility $p ; q_{\mathrm{ph}}$ is the quantity of service at facility $p$ consumed by household $h$; and $c_{\mathrm{ph}}$, $f_{\mathrm{ph}}$ and $s_{\mathrm{ph}}$ represent the unit costs, fees and subsidy, respectively, for facility $p$ for household $h$ [24].

To account for quality of care in the computation of public subsidy, a quality score needs to be developed for the facilities used by households. There is no standard approach for developing a measure for quality - a lot depends on the availability of data. In this paper, we did not have direct health care quality indicators, therefore we developed a proxy measure for quality using area (village)-level deprivation indicators (availability of water, electricity, energy source for cooking, education, etc.) [34]. These indicators were obtained from a cross-sectional, nationally representative survey of 5000 randomly selected households across Cambodia [35]. The indicators were transformed into binary variables with a value of 1 or 0 (available/not 
available, modern/traditional, high/low, etc.). The indicators had a Cronbach's alpha of 0.84 , indicating a relatively high internal consistency. For each area, the indicators were summed together to derive the quality index. To apply the index in a meaningful way, we chose an outcome measure $\left(o_{a}\right.$, i.e. infant mortality rate [IMR]), which was regressed on the quality index $\left(x_{a}\right)$ as shown in Eq. (2) (Fig. 1). The infant mortality data came from the Cambodia Inter-censal Population Survey 2013 and the National Report of Final Results of Cambodian 2008 Population Census [36, 37]. The quality index was log-transformed in order to obtain a better fit to the data because the outcome is a positively skewed count variable. A goodness-of-fit test was used to test for appropriate transformation of data [38]:

$o_{a}=\alpha_{0}+\alpha_{1} \ln \left(x_{a}\right)$,

where subscript $a$ denotes data at the area level.

Predicted values of the outcome were derived from the regression model, which was adjusted for the predicted mean (or the constant, $\alpha_{0}$, in a simple regression model) in order to obtain a ratio scale as the quality score for the BIA (Eq. 3):

$w_{a}=\alpha_{0} / \hat{o}_{a}$,

The reason for choosing a ratio scale was to avoid negative values in the estimated benefits. The final quality score was assigned to each facility in the area. This was done by simply mapping the facilities in each area and attributing the quality score for a particular area to all the facilities in that area.

Having developed the quality scores, we then applied them to weight the public subsidies received by households, to get the quality-adjusted or weighted subsidies (Eq. 4):

$\mathrm{WS}_{\mathrm{ph}}=S_{\mathrm{ph}} x_{\mathrm{ph}}$,

where $\mathrm{WS}_{\mathrm{ph}}$ is the quality-adjusted or weighted subsidy (Scenario 1) and $x_{\mathrm{ph}}$ is the quality score for facility $p$ used

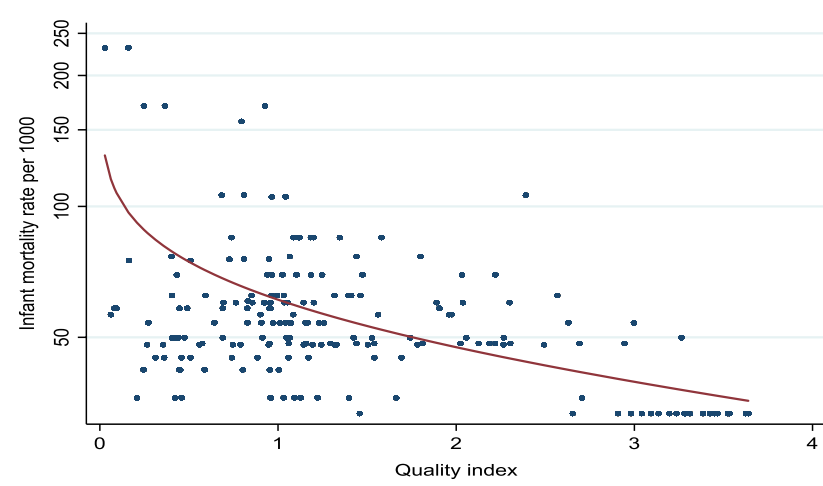

Fig. 1 Quality index fitted to an outcome measure-infant mortality rate by household $h$. An alternative approach to weighting the final subsidy received by households is to weight the unit cost for the subsector by the quality score. The cost incurred by providers in a particular subsector (e.g. health centre), under the constant unit cost assumption, is taken to be the same across the subsector. We assumed in this paper that the unit cost may vary depending on the location of the facility. For example, facilities in remote/rural areas are more likely to deliver poor-quality care at a higher unit cost due to limited economies of scale compared with those in urban areas. The amount of public subsidy captured by households is represented as shown in Eq. (5):

$$
\begin{aligned}
\mathrm{WS}_{\mathrm{ph}} & =C_{\mathrm{ph}}-F_{\mathrm{ph}}=\left(c_{\mathrm{ph}} \times x_{\mathrm{ph}}\right) q_{\mathrm{ph}}-f_{\mathrm{ph}} q_{\mathrm{ph}} \\
& =q_{\mathrm{ph}}\left(\left(c_{\mathrm{ph}} \times x_{\mathrm{ph}}\right)-f_{\mathrm{ph}}\right)=\mathrm{ws}_{\mathrm{ph}} q_{\mathrm{ph}},
\end{aligned}
$$

where $\mathrm{WS}_{\mathrm{ph}}$ is the subsidy after quality-adjustment of the unit cost (Scenario 2); $x_{\mathrm{ph}}$ is the quality score for facility $p$ used by household $h$; and $\mathrm{ws}_{\mathrm{ph}}$ is the subsidy for facility $p$ captured by household $h$.

\section{Application of Quality Scores to Weight Public Subsidies Using Data from Cambodia}

We illustrate the computation of public subsidies for health centre and hospital outpatient care received by households (grouped into wealth quintiles) using data from the crosssectional household survey referred to in the second paragraph of the Weighting Public Subsidies by Quality Score section. Full details of the sampling procedure and the range of data collected in this survey have been published elsewhere [35]. Total health expenditure data were extracted from the Cambodia National Health Accounts and health service utilisation data from the Annual Health Statistics Report 2012 [39], as well as the Cambodia Demographic and Health Survey 2014 [40]. These aggregate datasets were used to estimate the unit costs of outpatient care in the two subsectors. The unit costs were derived by dividing the total costs incurred in providing the health service (i.e. subsidies plus user fees) by the quantity of service utilised [24]. Table 1 shows the original (unadjusted) and quality-adjusted subsidies for health centres.

The data show a clear pro-poor distribution of the unadjusted subsidy, with the poorest quintile receiving around $31 \%$ of the total subsidy compared with only approximately $2.2 \%$ for the richest $20 \%$ of the population. The pattern of distribution of the subsidy mimics the quantity of service used across wealth quintiles - the poorest quintile accounted for the bulk of the utilisation of health centre services (nearly 33\%). This reflects limited OOP payments at the health centre level. When quality is taken into account, the percentage 
Table 1 Quality-adjusted subsidies by wealth quintile—health centre

\begin{tabular}{llrllrrrrr}
\hline Quintile & $\begin{array}{l}\text { Mean } \\
\text { quality } \\
\text { score }\end{array}$ & Quantity used & Percent $(\%)$ & $\begin{array}{l}\text { Unadjusted } \\
\text { subsidy }\end{array}$ & Percent (\%) & $\begin{array}{l}\text { Quality- } \\
\text { adjusted sub- } \\
\text { sidy: scenario } \\
1 *\end{array}$ & & $\begin{array}{l}\text { Percent }(\%) \\
\text { Quality- } \\
\text { adjusted sub- } \\
\text { sidy: scenario } \\
2 * *\end{array}$ \\
\hline Q1-poorest & 0.842 & 601,392 & 32.6 & $10,323,870$ & 31.0 & $9,045,190$ & 27.1 & $8,551,761$ \\
Q2 & 0.939 & 369,198 & 20.0 & $7,291,957$ & 21.9 & $6,691,296$ & 20.1 & $6,643,885$ \\
Q3 & 0.999 & 443,686 & 24.0 & $6,690,875$ & 20.1 & $6,393,449$ & 19.2 & $6,387,553$ \\
Q4 & 1.208 & 361,806 & 19.6 & $8,296,799$ & 24.9 & $10,306,626$ & 30.9 & $10,615,911$ & 31.9 \\
Q5-richest & 1.414 & 69,357 & 3.8 & $\mathbf{7 2 2 , 9 1 4}$ & 2.2 & 889,854 & 2.7 & $1,127,304$ & 3.4 \\
Total & $\mathbf{1 . 1 0 9}$ & $\mathbf{1 , 8 4 5 , 4 3 9}$ & $\mathbf{1 0 0 . 0}$ & $\mathbf{3 3 , 3 2 6 , 4 1 5}$ & $\mathbf{1 0 0 . 0}$ & $\mathbf{3 3 , 3 2 6 , 4 1 5}$ & $\mathbf{1 0 0 . 0}$ & $\mathbf{3 3 , 3 2 6 , 4 1 5}$ & $\mathbf{1 0 0 . 0}$ \\
\hline
\end{tabular}

*The unadjusted subsidy is weighted using the quality score to obtain the quality-adjusted subsidy

**The unit cost is weighted using the quality score to get an adjusted unit cost that is combined with the quantity of service used and fees paid to derive the quality-adjusted subsidy

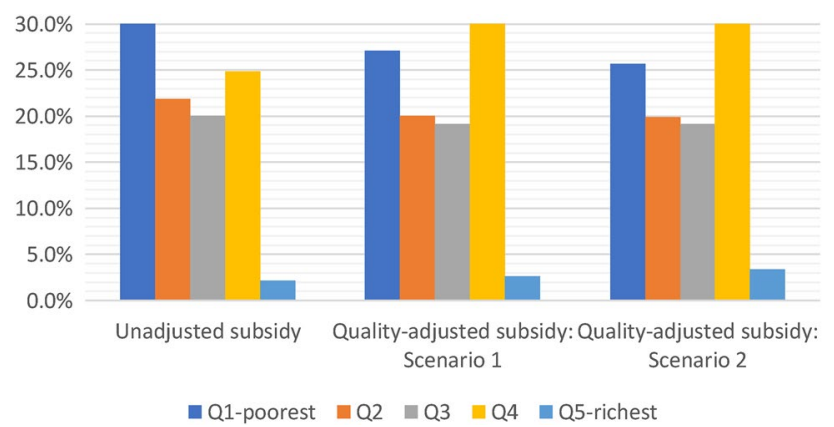

Fig. 2 Unadjusted and quality-adjusted subsidies—-health centre

share of the subsidy for the poorest quintile drops from 31 to $27.1 \%$ under Scenario 1 and to $25.7 \%$ under Scenario 2. This represents a decrease in the subsidy of approximately $13 \%$ and $17 \%$, respectively. By contrast, the share for the wealthiest quintile rises from 2.2 to $2.7 \%$ under scenario 1 and to $3.4 \%$ under scenario 2, representing an increase of about $23 \%$ and $55 \%$, respectively. The rise in the subsidy for the fourth quintile is also noteworthy; the percentage share of the subsidy for this quintile increased from 24.9 to $30.9 \%$ under scenario 1 and to $31.9 \%$ under scenario 2, a rise of
$24 \%$ and $28 \%$, respectively. Figure 2 shows the unadjusted and quality-adjusted subsidies.

Unlike distribution of the subsidy for health centres, the unadjusted subsidy for public hospital outpatient care was relatively evenly distributed, although the poorest quintile captured a slightly higher proportion $(21.0 \%)$ than the wealthiest quintile (18.8\%). This does not follow the utilisation pattern as seen with the health centre subsidy; for public hospitals, the poorest quintile accounted for the second largest share of unadjusted subsidy, although they had lower utilisation of health care services than any group except the fourth quintile. However, distribution of the subsidy turns pro-rich when quality is factored into the computation, as shown in Table 2.

The share of the subsidy for the poorest quintile falls from 21 to $16.3 \%$ under scenario 1 and to $14.7 \%$ under scenario 2 , a decline of $22 \%$ and $30 \%$, respectively. Conversely, the share for the wealthiest quintile rises substantially from 18.8 to $25.2 \%$ (about a $34 \%$ increase) under scenario 1 and to $29.1 \%$ (more than 50\%) under scenario 2. Figure 3 shows the unadjusted and quality-adjusted subsidies across wealth quintiles under the different scenarios.

Table 2 Quality-adjusted subsidies by wealth quintile—public hospital outpatient

\begin{tabular}{|c|c|c|c|c|c|c|c|c|c|}
\hline Quintile & $\begin{array}{l}\text { Mean } \\
\text { quality } \\
\text { score }\end{array}$ & Quantity used & Percent (\%) & $\begin{array}{l}\text { Unadjusted } \\
\text { subsidy }\end{array}$ & Percent (\%) & $\begin{array}{l}\text { Quality- } \\
\text { adjusted } \\
\text { subsidy: } \\
\text { scenario } 1\end{array}$ & Percent (\%) & $\begin{array}{l}\text { Quality- } \\
\text { adjusted } \\
\text { subsidy: } \\
\text { scenario } 2\end{array}$ & Percent (\%) \\
\hline Q1-poorest & 0.771 & 129,062 & 17.7 & $35,279,288$ & 21.0 & $27,284,479$ & 16.3 & $24,613,074$ & 14.7 \\
\hline Q2 & 0.860 & 148,442 & 20.4 & $38,644,763$ & 23.1 & $33,081,867$ & 19.7 & $30,915,457$ & 18.4 \\
\hline Q3 & 0.915 & 134,482 & 18.4 & $32,833,249$ & 19.6 & $32,130,355$ & 19.2 & $30,640,538$ & 18.3 \\
\hline Q4 & 1.107 & 126,559 & 17.4 & $29,387,283$ & 17.5 & $32,920,992$ & 19.6 & $32,724,960$ & 19.5 \\
\hline Q5-richest & 1.295 & 190,664 & 26.1 & $31,494,287$ & 18.8 & $42,221,177$ & 25.2 & $48,744,840$ & 29.1 \\
\hline Total & 1.016 & 729,209 & 100.0 & $167,638,870$ & 100.0 & $167,638,870$ & 100.0 & $167,638,870$ & 100.0 \\
\hline
\end{tabular}




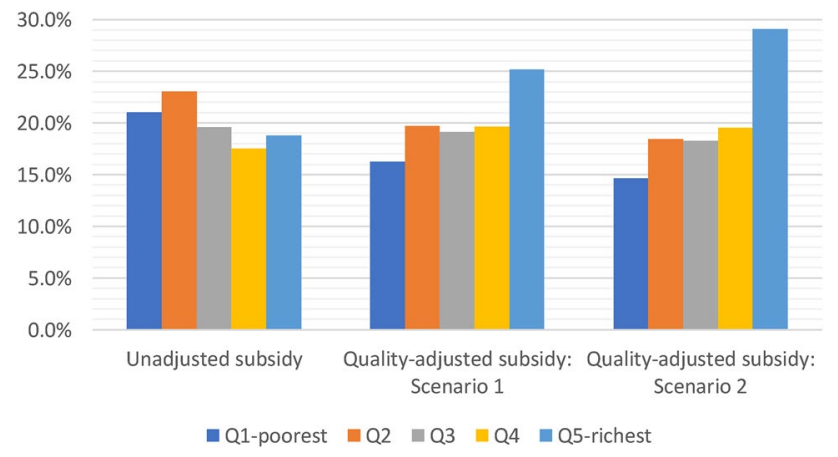

Fig. 3 Unadjusted and quality-adjusted subsidies-hospital outpatient care. $Q x$ quintile $\mathrm{x}$

\section{Discussion}

The analysis above highlights the potential for under/overestimating the amount of public subsidy for health care captured by households through their use of health services if the quality of service is not accounted for. As the illustrations in Tables 1 and 2 demonstrate, distribution of the health centre subsidy, while remaining relatively pro-poor, was less so after accounting for quality. On the other hand, the public hospital outpatient subsidy changed from propoor to significantly pro-rich. Traditional BIA computes public subsidy accrued to households by combining the quantity of health services used and the unit cost per service, while subtracting any OOP payments made for using the service [41]. In many LMICs, significant disparities exist in the quality of health services [23], and low-quality services ought not be valued the same as a high-quality services when computing subsidy/benefit from public spending. Indeed, low-quality services may not only provide limited benefit to the user but may also even be harmful to their health, leading to higher OOP expenditure [42]. Defining and measuring quality of health care, as noted earlier, is complicated but there are good leads in the literature, starting with the Institute of Medicine's definition [30] and the measurement framework of Donabedian [43]. What is critical for this paper is how to develop a quality score that could be applied to adjust the public subsidy captured by households.

It is often difficult to access datasets that contain variables on all three dimensions of quality, i.e. structure, process and outcomes [43]. A major limitation of this paper is the use of area-level data to proxy quality of care. As a starting point, one may generate a quality index using structural quality indicators from survey instruments similar to the World Health Organization's (WHO) Service Availability and Readiness Assessment (SARA) monitoring system [44]. However, the extensive collection of facility data may be prohibitive in cost and these may be sourced from secondary datasets made available through global agencies such as the WHO, World Bank or United State Agency for International Development (USAID). The World Bank, for example, conducts health facility surveys, in different countries, that incorporate most of the SARA indicators which can be used to assess quality of care. It is worth noting the limitations of depending on structural indicators to assess quality. The association between inputs to care and quality of care delivered is not always positive [45], albeit not having the required inputs may constrain any serious efforts to deliver quality care. Where researchers have the opportunity to collect primary data, they should explore opportunities for complementing measures of structural quality with measures of process quality using tools such as medical records, patient exit interviews, direct observation of provider-client interactions, or clinical vignettes [42]. There is also a growing interest in the use of standardised patients to measure the quality of care in LMICs [46, 47].

\section{Conclusion}

This paper has demonstrated that it is possible to account for quality of care in computing the public subsidy for health care received by households using BIA.

Acknowledgements The African Economic Research Consortium (AERC) provided funding for this work as part of its Healthcare Financing in Africa Project. However, the views expressed in this paper are entirely those of the authors. We acknowledge the contributions of Dr Por Ir, Dr Bart Jacobs and the entire CHEF team that implemented the Cambodian Health Financing and Equity study from which data were borrowed for the illustrations in this paper.

Author Contributions AA and VW: conceived the research; AA: developed the approach for weighting public subsidies by the quality scores, and analysed the household survey and expenditure data from Cambodia to illustrate the approach; NM: conducted all the statistical analyses in connection with the development of the quality scores, including extracting the required data from secondary sources; AA, VW and NM: contributed to reviewing the literature, interpreting the results and drafting the paper. All authors read and approved the final submission.

\section{Compliance with Ethical Standards}

Conflict of Interest Augustine Asante, Nicola Man and Virginia Wiseman declare no conflicts of interest.

Ethical Standards This work uses publicly available data that have received ethics approval and therefore further ethical review is not required.

Open Access This article is licensed under a Creative Commons Attribution-Non-commercial 4.0 International License, which permits any non-commercial use, sharing, adaptation, distribution and reproduction in any medium or format, as long as you give appropriate credit to the 
original author(s) and the source, provide a link to the Creative Commons licence, and indicate if changes were made. The images or other third party material in this article are included in the article's Creative Commons licence, unless indicated otherwise in a credit line to the material. If material is not included in the article's Creative Commons licence and your intended use is not permitted by statutory regulation or exceeds the permitted use, you will need to obtain permission directly from the copyright holder. To view a copy of this licence, visit http://creativecommons.org/licenses/by-nc/4.0/.

\section{References}

1. World Health Organization. Health in 2015: from MDGs, Millennium Development Goals to SDGs, Sustainable Development Goals. Geneva: World Health Organization; 2015.

2. World Health Organization. The World Health Report 2013research for universal health coverage. Geneva: World Health Organization; 2013.

3. World Health Organization. Tracking universal health coverage: 2017 global monitoring report. Geneva: World Health Organization; 2017.

4. Hart JT. The inverse care law. Lancet. 1971;297(7696):405-12.

5. Davoodi HR, Tiongson ER, Asawanuchit SS. Benefit incidence of public education and health spending worldwide: evidence from a new database. Pov Public Policy. 2010;2:5-52.

6. Balarajan Y, Selvaraj S, Subramanian SV. Health care and equity in India. Lancet. 2011;377:505-15.

7. Wagstaff A, Flores G, Smitz M-F, Hsu J, Chepynoga K, Eozenou P. Progress on impoverishing health spending in 122 countries: a retrospective observational study. Lancet Glob Health. 2018;6:e180-92.

8. Bredenkamp C, Buisman LR. Financial protection from health spending in the Philippines: policies and progress. Health Policy Plan. 2016;31:919-27.

9. World Health Organization: Sustainable health financing structures and universal coverage: 64th World Health Assembly agenda item 13.4. Geneva: World Health Organization, World Health Assembly; 2011. http://apps.who.int/gb/ebwha/pdf.

10. Fernandes Antunes A, Jacobs B, de Groot R, Thin K, Hanvoravongchai P, Flessa S. Equality in financial access to healthcare in Cambodia from 2004 to 2014. Health Policy Plan. 2018;33:906-19.

11. Chhun C, Kimsun T, Yu G, Ensor T, McPake B. Catastrophic payments and poverty in Cambodia: evidence from Cambodia Socio-Economic Surveys 2004, 2007, 2009, 2010 and 2011. Phnom Penh: Cambodia Development Resource Institute; 2015.

12. Tangcharoensathien V, Patcharanarumol W, Ir P, Aljunid SM, Mukti AG, Akkhavong K, et al. Health-financing reforms in southeast Asia: challenges in achieving universal coverage. Lancet. 2011;377:863-73.

13. Han SM, Rahman MM, Rahman MS, Swe KT, Palmer M, Sakamoto $\mathrm{H}$, et al. Progress towards universal health coverage in Myanmar: a national and subnational assessment. Lancet Glob Health. 2018;6:e989-97.

14. Asante AD, Irava W, Limwattananon S, Hayen A, Martins J, Guinness $\mathrm{L}$, et al. Financing for universal health coverage in small island states: evidence from the Fiji Islands. BMJ Glob Health. 2017;2:e000200

15. Ministry of Health, Republic of Indonesia: Health Financing and Universal Health Coverage: Policy Briefs. Indonesia: Australia Indonesia Partnership for Health Systems Strengthening; 2015. http://aiphss.org/policy-notes-2015.pdf.

16. Wiseman $\mathrm{V}$, et al. An evaluation of health systems equity in Indonesia: study protocol. Int J Equity Health. 2018;17(1):138.
17. Tangcharoensathien V, Limwattananon S, Patcharanarumol W, Thammatacharee J. Monitoring and evaluating progress towards universal health coverage in Thailand. PLoS Med. 2014;11:e1001726.

18. Chahed MK, Arfa C. Monitoring and evaluating progress towards Universal Health Coverage in Tunisia. PLoS Medicine. 2014;11:e1001729.

19. Reich MR, Harris J, Ikegami N, Maeda A, Cashin C, Araujo EC, et al. Moving towards universal health coverage: lessons from 11 country studies. Lancet. 2016;387:811-6.

20. Cotlear D, Nagpal S, Smith O, Tandon A, Cortez R. Going universal: how 24 developing countries are implementing universal health coverage from the bottom up. Washington, DC: The World Bank; 2015.

21. Van Minh H, Pocock NS, Chaiyakunapruk N, Chhorvann C, Duc HA, Hanvoravongchai P, et al. Progress toward universal health coverage in ASEAN. Glob Health Action. 2014;7:1.

22. Asante A, Price J, Hayen A, Jan S, Wiseman V. Equity in health care financing in low- and middle-income countries: a systematic review of evidence from studies using benefit and financing incidence analyses. PLoS One. 2016;11:e0152866.

23. Kruk ME, et al. High-quality health systems in the Sustainable Development Goals era: time for a revolution. Lancet Glob Health. 2018;6(11):e1196-252.

24. Wagstaff A. Benefit-incidence analysis: are government health expenditures more pro-rich than we think? Health Econ. 2012;21:351-66.

25. Asante AD, Price J, Hayen A, Irava W, Martins J, Guinness L, et al. Assessment of equity in healthcare financing in Fiji and Timor-Leste: a study protocol. BMJ Open. 2014;4(12):e006806.

26. Mills A, Ataguba JE, Akazili J, Borghi J, Garshong B, Makawia $S$, et al. Equity in financing and use of health care in Ghana, South Africa, and Tanzania: implications for paths to universal coverage. Lancet. 2012;380(9837):126-33.

27. Demery L. Benefit incidence: a practitioner's guide. Washington, DC: The World Bank; 2000.

28. World Bank. Health equity and financial protection reportGhana. Washington, DC: The World Bank; 2012.

29. World Bank. Health equity and financial protection report - Mongolia. Washington, DC: The World Bank; 2012.

30. Lohr KN. Medicare: a strategy for quality assurance. New York: National Academies Press; 1990.

31. World Health Organization. Toolkit on monitoring health systems strengthening: service delivery (draft). Geneva: World Health Organization; 2008.

32. Donabedian A. The quality of care: how it can be assessed? J Am Med Assoc. 1988;260(12):1743-8.

33. O'Donnell O, Van Doorslaer E, Wagstaff A, Lindelow M. Analyzing Health equity using household survey data: a guide to techniques and their implementation. Washington, DC: World Bank Publications; 2008.

34. Ashworth M, Seed P, Armstrong D, Durbaba S, Jones R. The relationship between social deprivation and the quality of primary care: a national survey using indicators from the UK Quality and Outcomes Framework. Br J Gen Pract. 2007;57:441.

35. Wiseman V, et al. System-wide analysis of health financing equity in Cambodia: a study protocol. BMJ Glob Health. 2017;2(1):e000153.

36. National Institute of Statistics Cambodia. Cambodia inter-censal population Survey (CIPS) 2013: analysis of CIPS results, report 1 - estimates of fertility and mortality. Phnom Penh: Ministry of Planning; 2013.

37. Statistics Bureau of Japan. National Report of Final Results of Cambodian 2008 Population Census (Analytical Reports). Phnom Penh: Statistics Bureau of Japan; 2009. https://www.stat.go.jp/ english/info/meetings/cambodia/pc08_arp.html. 
38. Tukey JW. One degree of freedom for non-additivity. Biometrics. 1949;5:232-42.

39. Ministry of Health and World Health Organization. Annual health statistics report 2012. Phomn Penh: Ministry of Health; 2012.

40. Kosal S, Satia C, Kheam T, Chinda P, Mondol L, Phirun L, et al. Cambodia demographic and health survey 2014. Phnom Penh: National Institute of Statistics; 2015.

41. McIntyre D, Ataguba JE. How to do (or not to do) ... a benefit incidence analysis. Health Policy Plan. 2011;26:174-82.

42. World Health Organization. Delivering quality health services: a global imperative for universal health coverage. Geneva: World Health Organization; 2018.

43. Donabedian A. The definition of quality and approaches to its assessment. Chicago: Health Administration Press; 1980.

44. World Health Organization. Service availability and readiness assessment (SARA): an annual monitoring system for service delivery: implementation guide. Geneva: World Health Organization; 2015.

45. Leslie HH, Sun Z, Kruk ME. Association between infrastructure and observed quality of care in 4 healthcare services: a crosssectional study of 4300 facilities in 8 countries. PLoS Med. 2017; 14:e1002464.

46. Kwan A, Daniels B, Bergkvist S, Das V, Pai M, Das J. Use of standardised patients for healthcare quality research in low- and middle-income countries. BMJ Glob Health. 2019;4:e001669.

47. Wiseman V, Lagarde M, Kovacs R, On behalf of Members of the Standardised Patients Working Group, et al. Using unannounced standardised patients to obtain data on quality of care in lowincome and middle-income countries key challenges and opportunities. BMJ Global Health. 2019;4(5):e001908. 